\title{
Neuropathic Pain: Treatment Using Natural Therapeutics
}

\author{
Mahender Singh Rawat, Kuldeep Nigam, Shweta Dang* \\ Department of Bioetchnology, Jaypee Institute of Information Technology, A-10, Sec 62, Noida 201307, Uttar Pradesh, India
}

Address for Correspondence: Shweta Dang, shweta.dang@jiit.ac.in

Keywords

Neuropathic pain; Analgesic; Clinical disorder; Medicinal plants.

\begin{abstract}
Neuropathic pain arises from peripheral nerve or spinal cord injury and is a clinical disorder characterized by grouping of spontaneous pain, abnormally heightened sensitivity to pain, tactile allodynia. Neuropathic pain remains a major clinical problem as it is poorly relieved by conventional analgesics and their side effects on body is also a major concern. Despite of all progress that occurred till now for the development of therapy, there is still a need for improvement. Natural medicinal plant or their plant products provide alternative approach to overcome this problem. Variety of plant derived substance such as alkaloids, terpenoids and flavonoid are reported as analgesic substances for the treatment of neuropathic pain. It is reported that around $25 \%$ of the medicinal drugs used by developed countries are based on the plants and their derivatives. According to World Health Organization (WHO), $80 \%$ of the world population reside on traditional medicine for their primary health need. The use of medicinal plant for the treatment of various diseases are showing considerable economic benefit in the Gross Domestic Product (GDP) of the country. This is a summarized study of some existing medicinal plants showing efficacy for neuropathic pain. (C) 2016 iGlobal Research and Publishing Foundation. All rights reserved.
\end{abstract}

Conference Proceedings: International Conference on Advances in Plant and Microbial Biotechnology (PMB2017); JIIT, Noida: February 02-04, 2017

Indo Global Journal of Pharmaceutical Sciences( ISSN 22491023 ; CODEN- IGJPAI; NLM ID: 101610675) indexed and abstracted in EMBASE(Elsevier), SCIRUS(Elsevier),CABI, CAB Abstracts, Chemical Abstract Services(CAS), American Chemical Society(ACS), Index Copernicus, EBSCO, DOAJ, Google Scholar and many more. For further details, visit http://iglobaljournal.com 